\title{
Simulation speaks for itself: Building speech- language pathology students' confidence through high quality simulation within a workplace clinical placement
}

\author{
J. Shorland, C. Morris \& D. Stephens
}

\begin{abstract}
Introduction: This study investigated student perceptions of a brief standardised patient programme within a speech-language pathology workplace clinical placement. The simulation programme was designed to allow practise of communication and interpersonal skills with standardised patients before working with real patients in the healthcare environment.

Methods: Speech-language pathology students $(\mathrm{n}=30)$ completing their final-year placement at an Australian metropolitan healthcare provider participated in this programme between 2014 and 2016. Students routinely completed anonymous pre-post experience surveys as part of the programme. A retrospective pre-post study design was used to determine the programme's impact on perceived anxiety and perceived confidence for communication and interpersonal skills. A qualitative analysis of written feedback was also utilised to further understand student perceptions of the programme.
\end{abstract}

Results: Reported levels of anxiety, when anticipating interaction with real patients, significantly reduced $(p<0.05)$. Further, confidence across all communication and interpersonal skills increased significantly $(p<0.05)$ post programme. Thematic analysis of written feedback showed three themes related to student perceptions and learning preferences.

Speech Pathology Department, Caulfield Hospital, Alfred Health, Melbourne, Australia

\author{
Correspondence \\ Joanna Shorland \\ Senior Speech Pathologist \\ Speech Pathology Department \\ Caulfield Hospital \\ Alfred Health \\ 260 Kooyong Road, Caulfield \\ Melbourne, VIC 3162 \\ Australia \\ Ph: +61 390766281 \\ Email: j.shorland@alfred.org.au
}


Conclusions: Although actual learning outcomes were not investigated, it appears that the utilisation of a brief standardised patient learning programme, embedded within a speech-language pathology workplace placement, is a promising way to target student competencies, such as communication and interpersonal skills.

Keywords: speech-language pathology; standardised patients; clinical education.

\section{Introduction}

The healthcare environment provides unique challenges for students on a workplace clinical placement. They are required to work with patients who are unwell or who have major changes to their cognitive, communicative and physical function. Students must quickly adapt to this environment and utilise a high level of communication and interpersonal skills to provide appropriate assessment and intervention. Evidence suggests that interacting with patients in a hospital setting can be daunting for students (Levett-Jones, Pitt, Courtney-Pratt, Harbrow, \& Rossiter, 2015). Explicit resources and time must be devoted to nurturing patient-centred communication and interpersonal skill in students.

Simulated learning is an educational tool utilised in healthcare. It involves participation in a guided-learning experience that emulates a real-world experience. Recent published examples of simulated learning within the field of speech-language pathology have included human patient simulation within the area of paediatric dysphagia (Ward et al., 2015) and a simulation programme with standardised patients depicting parents of children with speech delays (Hill, Davidson, \& Theodoros, 2013). Standardisedpatient programmes particularly lend themselves to communication practice. A standardised patient is an actor who has been trained to depict an illness or condition in a standardised fashion for the purposes of clinical education (Barrows, 1993). The use of standardised patients as a form of simulated learning was developed in the 1960s (Barrows \& Abrahamson, 1964). It has become established within clinical education in the medical profession since this time (Barrows, 1993). It is now viewed as an effective tool that can be used to teach a variety of skills and competencies in other health professions. For example, this is evident in fields that include nursing (Bornais, Raiger, Krahn, \& El-Masri, 2012; McKenna, Innes, French, Streitberg, \& Gilmour, 2011), physiotherapy (Dennis, Ng, \& Furness, 2017; Watson et al., 2012), occupational therapy (Herge et al., 2013) and dietetics (Schwartz, Rothpletz-Puglia, Denmark, \& Byham-Gray, 2015). Literature reviews have indicated emerging use of standardised patients within speech-language pathology clinical education contexts and highlighted the potential untapped use of this tool in the profession (Hill, Davidson, \& Theodoros, 2010; Macbean, Theodoros, Davidson, \& Hill, 2013; Zraick, 2012).

Benefits pertaining to standardised patient use in clinical education have been well documented within healthcare literature. It is a method of learning that students are generally satisfied with (Dennis et al., 2017; Halkett, McKay, \& Shaw, 2011; Herge et al., 2013; Hill et al., 2013; McKenna et al., 2011; Parikh et al., 2015; Syder, 1996; Zraick, Allen, \& Johnson, 2003). As a general concept, simulated learning allows educators to provide students with a safe practice zone (Gore \& Thomson, 2016; 
Kneebone, Scott, Darzi, \& Horrocks, 2004). Evidence from two parallel randomised controlled trials (RCT 1, $\mathrm{n}=1$ 192; RCT 2, $\mathrm{n}=178$ ) from the field of physiotherapy showed that the use of standardised patients could replace $25 \%$ of a clinical placement without negatively impacting on outcomes (Watson et al., 2012).

Standardised-patient programmes have been used within healthcare fields to target student communication. Areas of focus have included history taking (Halkett et al., 2011), conflict resolution (Beattie et al., 2014) and challenging clinical conversations (Parikh et al., 2015). Studies within speech-language pathology have generally been small in nature and heterogeneous in design (e.g., Bressmann \& Eriks-Brophy, 2012; Syder, 1996; Zraick et al., 2003). A larger and more targeted study has considered speech-language pathology students' perceptions of their anxiety and confidence levels before and after a foundation skills programme that included work with standardised patients. Most notably, results showed that undergraduate students $(n=131)$ perceived a significant drop in anxiety levels and an increase in confidence around interacting with real patients in a range of skills that related to communication (Hill et al., 2013). The aforementioned speech-language pathology studies are illustrative of how standardised patients can be used as an educational tool across a variety of clinical skill areas outside of the traditional workplace clinical-placement setting.

This study aimed to investigate whether participation in a brief standardised patient learning programme targeting communication and interpersonal skills and embedded within a speech-language pathology workplace clinical placement:

- reduced students' perceived anxiety levels around the idea of interacting with real patients prior to their clinical placement

- improved students' perceived confidence in their anticipated ability to use eight communication- and interpersonal-based skills with real patients during their clinical placement.

This study also aimed to investigate student perceptions of this programme.

\section{Method}

\section{Study design}

This study involved a pre-post study design that included quantitative survey data along with qualitative analysis of students' written comments. Relevant ethics committee approval was granted by the Alfred Health Ethics Committee.

\section{Participants}

Participants $(\mathrm{n}=30)$ were final-year speech-language pathology students undertaking clinical placement within an Australian metropolitan healthcare network from 2014 to 2016. Being final-year students, they all would have had some exposure to a workplace setting and, thus, some opportunity to be exposed to their own learning needs. Six programmes were run over this period, with an average of five students per programme. Twenty-eight of the students were female and two were male. 


\section{The standardised-patient learning programme}

This programme occurred on either day two or three of the students' final-year 30- to 33day clinical placement. The programme ran for approximately four hours. To enrich the authenticity of the experience, it took place in a simulation facility set up to replicate the hospital environment. Two to three experienced speech-language pathologists facilitated the programme. The students were all made aware that the programme was a learning experience rather than an assessment task. The lack of actual or perceived assessment was considered important to promote the concept of learning rather than grade achievement.

Students participated in a pre-programme communication skills tutorial that focused on interpersonal behaviour and communication skills specific to the healthcare environment. It also included information about the standardised learning programme itself, as the students had little, if any, previous exposure to this method of learning. Students were provided with case scenarios on the day of the programme and encouraged to role play the scenarios within their student cohort. One hour of preparation time was allowed. The facilitators were on call to answer questions about the scenarios and the programme itself; however, they did not remain in the room with the students during this preparation session.

Two standardised patient scenarios were developed by a senior speech-language pathologist experienced in clinical education. The scenarios were reviewed for content and clinical authenticity by other experienced members of the speech-language pathology team. The first scenario focused on educational counselling to a patient with dysphagia. Students were required to communicate information around swallowing function and modified diet prescription to a patient who was averse to following speech-language pathology recommendations. The second scenario involved screening the cognitive communication function of a patient with a traumatic brain injury. Both standardised patients displayed varying challenging interpersonal behaviours, including aggression and disinhibition. Students had 10-15 minutes to individually participate in each scenario. Students not participating in the scenario observed the interactions.

Two actors experienced in standardised patient work took part in the programme. Consistency of actors was maintained throughout the six programmes. Prior to implementation of the programme, the actors were provided with detailed written information about the scenarios, their roles, and the goals of the programme.

Feedback and opportunity for student reflection and discussion were important inclusions in this supported learning programme. Immediate verbal feedback was provided to each student from the facilitator after their standardised patient interaction. During particularly challenging interactions, the facilitator would pause the scenario, discuss the challenges and encourage the student to consider a different approach. This type of online technique can be exploited during work with standardised patients in order that student reflection is supported by an immediate context at no cost to a real patient (Barrows, 1993). At the conclusion of the programme, group feedback was provided by the facilitators and actors. Students were also encouraged to reflect on the experience, which usually led to an open and dynamic discussion. 
Students routinely completed anonymous and de-identified pre-post-programme surveys as a means of self-reflection and to inform facilitators on the usefulness of the programme. Surveys were adapted from Hill et al. (2013). Adaptions were minor in nature and pertained to content changes in line with the design and aims of the current study. This included the omission of a question around group work with standardised patients and the addition of a question around students' perceptions of the usefulness of a standardised patient experience within a workplace clinical placement. The pre-programme survey prompted students to rate their perceived anxiety levels around the idea of interacting with real patients and their perceived confidence in their anticipated ability to use eight communication- and interpersonal-based skills with real patients. Perceived anxiety was rated on a 5-point ordinal scale and perceived confidence was rated on a 4-point ordinal scale. Immediately following participation in the programme, students completed the post-programme component of the survey. This required them to, again, rate their perceived anxiety and confidence levels using the same scales. The post-programme survey also addressed students' thoughts on the usefulness of the programme, with free-text boxes for comment.

\section{Data analysis}

\section{Quantitative analysis}

De-identified pre-post anxiety and confidence survey data were analysed using Statistical Package for the Social Sciences (SPSS) version 16.0 (SPSS, 2007). For non-parametric paired data, the Wilcoxon signed-rank test was used. Data were analysed to determine the impact of the programme on students' perceived anxiety levels around the idea of interacting with real patients and on students' perceived confidence in various interpersonal and communication skill areas. The alpha level was set at 0.05 . Descriptive statistics were also used to analyse responses to questions around the inclusion of the programme within this clinical placement.

\section{Qualitative analysis}

A thematic analysis was conducted on the free-text responses in the post-programme surveys to glean further information about students' perceptions of the programme. This was important, as it was not clear how favourably students would perceive a programme with actors playing patients within a facility that was able to provide exposure to real patients. Free-text data was manually coded using an open-coding approach. Once patterns and links between codes became apparent, units of coded data were compiled together into categories. Finally, overarching themes that were seen to reflect the students' perceptions of the standardised-learning programme were identified. Two of the researchers independently analysed the data before collaborating on findings to consider any gaps in analysis. This approach was adopted as a form of triangulation (Lincoln \& Guba, 1985). A third researcher, then, audited the data trail to ensure that there was a logical path from the raw data to the themes (Corbin $\&$ Strauss, 2008). 


\section{WORK PLACEMENT AND STANDARDISED PATIENTS}

\section{Results}

\section{Quantitative results}

As illustrated in Table 1, prior to the learning programme, just over three quarters of students reported feeling moderately or severely anxious (five students reported feeling severely anxious) about the concept of working with real patients on clinical placement. Following the learning programme, $72 \%$ of students reported feeling not anxious or slightly anxious. Of the remaining students, $28 \%$ reported feeling moderately anxious, and no students reported feeling severely anxious. Changes in anxiety levels were statistically significantly $(p<0.001)$. Following the learning programme, students reported statistically-significant confidence gains in their anticipated ability to apply all eight surveyed communication and interpersonal skills with real patients (Table 2).

Table 1

Student Clinicians' Pre-Post Programme Ratings of Perceived Anxiety Levels When Anticipating Working With Real Patients $\left(\mathrm{n}=29^{* *}\right)$

\begin{tabular}{l|c|c|c} 
Perceived Anxiety Level & Pre-Programme & Post-Programme & $\begin{array}{l}\text { Wilcoxon } \\
\text { Signed-Rank } \\
\text { Test Values* }\end{array}$ \\
\hline Not anxious/slightly anxious & $24 \%(n=7)$ & $72 \%(n=21)$ & $<0.001$ \\
\hline Moderately anxious/severely anxious & $76 \%(n=22)$ & $28 \%(n=8)$ & $<0.001$ \\
\hline
\end{tabular}

* Statistically-significant result $p<0.05$

** Note: one student clinician did not complete these questions.

Table 2

Student Clinicians' Pre-Post Ratings of Confidence in Communication Skills When Anticipating Working With Real Patients $(\mathrm{n}=30)$

\begin{tabular}{l|c|c|c|c|c}
\multirow{2}{*}{ I feel confident in my ability to ...** } & \multicolumn{2}{|l|}{$\begin{array}{l}\text { Pre-Programme } \\
\text { Ratings }\end{array}$} & \multicolumn{2}{l|}{$\begin{array}{l}\text { Post-Programme } \\
\text { Ratings }\end{array}$} & $\begin{array}{l}\text { Wilcoxon } \\
\text { Signed-Rank } \\
\text { Test Values* }\end{array}$ \\
\cline { 2 - 6 } & Mean & SD & Mean & SD & $<0.001$ \\
\hline Establish rapport with a client & 3.03 & 0.41 & 3.46 & 0.50 & 0.01 \\
\hline Explain my professional role to a client & 3.00 & 0.52 & 3.33 & 0.47 & 0.02 \\
\hline $\begin{array}{l}\text { Use interpersonal skills such as reflective } \\
\text { listening and appropriate use of questions }\end{array}$ & 2.93 & 0.52 & 3.16 & 0.37 & $<0.001$ \\
\hline Identify key clinical information & 2.76 & 0.62 & 3.16 & 0.46 & $<0.001$ \\
\hline Interview clients about personal information & 2.60 & 0.62 & 3.16 & 0.53 & $<0.001$ \\
\hline Provide information to clients & 2.73 & 0.58 & 3.10 & 0.30 & $<0.001$ \\
\hline $\begin{array}{l}\text { Interact with clients with challenging } \\
\text { behaviours }\end{array}$ & 2.20 & 0.71 & 2.93 & 0.44 & \\
\hline Interact in a professional manner & 3.26 & 0.52 & 3.56 & 0.56 & 0.02 \\
\hline
\end{tabular}

* Statistically significant result $p<0.05$

** Responses were based on a 4-point ordinal scale where $1=$ strongly disagree and $4=$ strongly agree 
WORK PLACEMENT AND STANDARDISED PATIENTS

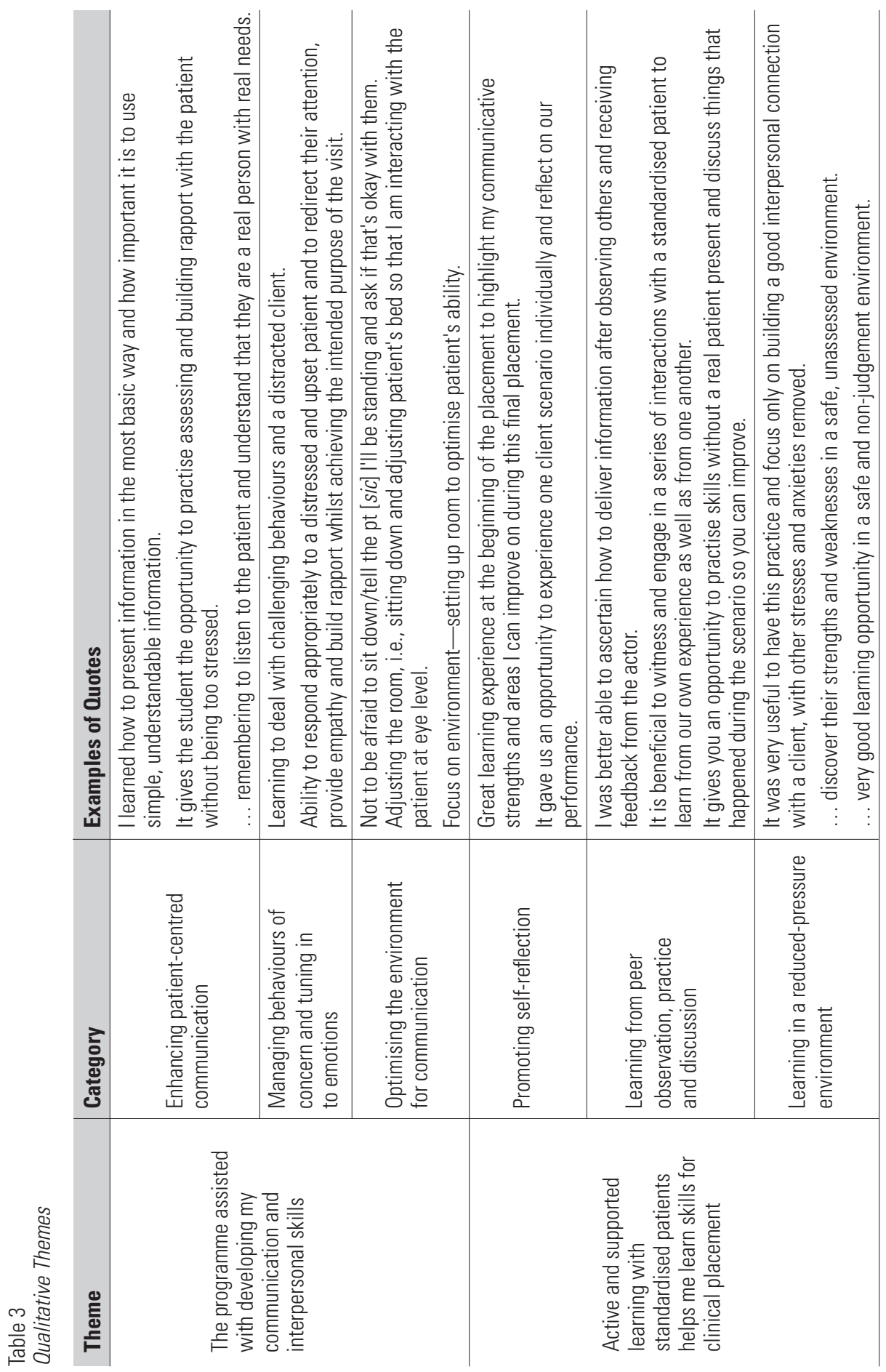


WORK PLACEMENT AND STANDARDISED PATIENTS

\begin{tabular}{|c|c|c|c|c|c|}
\hline 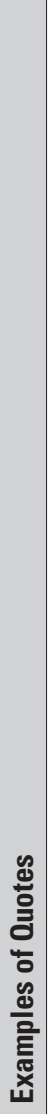 & 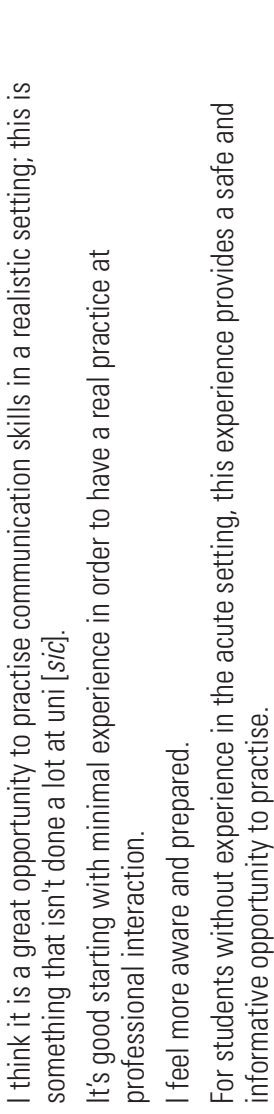 & 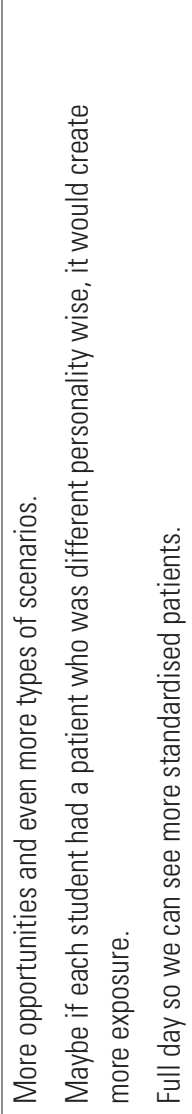 & 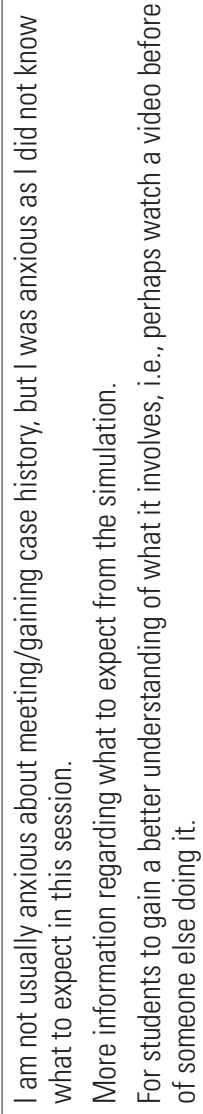 & 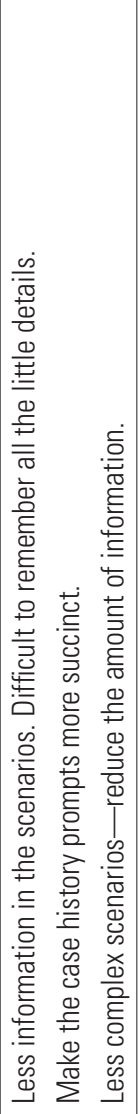 & 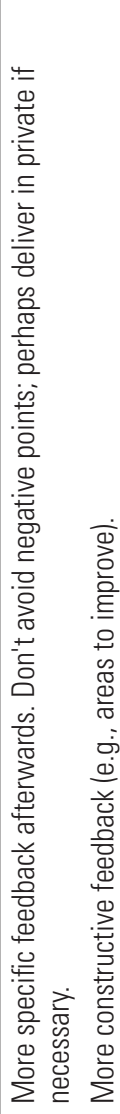 \\
\hline 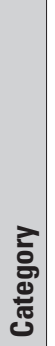 & 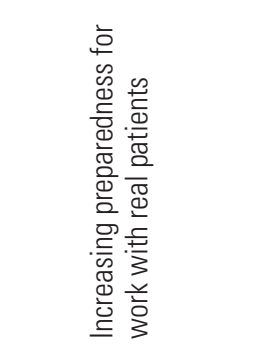 & 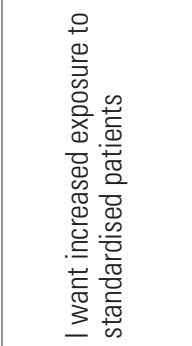 & 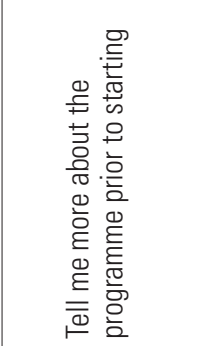 & 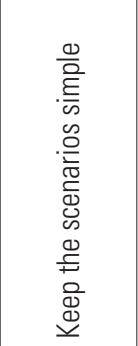 & 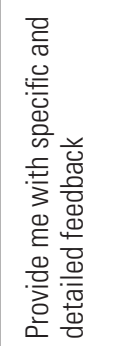 \\
\hline 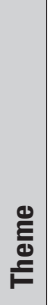 & 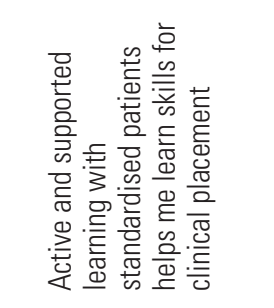 & & 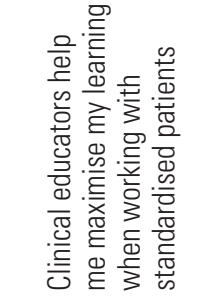 & & \\
\hline
\end{tabular}


A descriptive analysis was conducted on two questions that addressed the perceived worth of the standardised patient programme and its timing within the clinical placement. All students involved in the programme $(n=30)$ indicated that they thought it would be useful for future student groups to have practice with standardised patients. With regards to the timing of the programme, $93 \%$ of students thought it was beneficial for the programme to be at the beginning of their placement. Two respondents would have preferred the programme to be held in the second week of placement.

\section{Qualitative results}

Thematic analysis of students' written feedback led to three major themes that encapsulated the viewpoints of the students. These were: 1) The programme assisted with developing my communication and interpersonal skills, 2) Active and supported learning with standardised patients helps me build skills for clinical placement, and 3) Clinical educators maximise my learning when working with standardised patients (Table 3).

It is expected practice to provide some demographics with participant quotations to support the credibility of data by ensuring that they are drawn from a range of participants. In this study, they are not given to preserve anonymity due to the relative homogeneity of respondents; any outliers might be easily identified.

\section{Theme 1: The programme assisted with developing my communication and interpersonal skill.}

Students commented that working with the standardised patients helped them to focus on and enhance their patient-centred communication. Specifics mentioned by students included building rapport, using terminology that was accessible to the individual and "remembering to listen to the patient and understand that they are a real person with real needs". The students also reported learning new skills to manage behaviours of concern. Taking measures to optimise the hospital environment to support communication was also mentioned, for example, "sitting down and adjusting the patient's bed so that I am ... at eye level".

\section{Theme 2: Active and supported learning with standardised patients helps me learn skills for clinical placement}

This theme evolved from commonalities in students' descriptions of the learning experience and its perceived worth within a clinical placement. Learning was deemed to be an active process. This was due to not only the nature of work with standardised patients but also the active role the programme encouraged students to take in their own learning. They felt that it prompted self-reflection by pushing them to explore their own communicative strengths and weaknesses and identify the areas that they needed to work on within the placement. Students gave positive feedback on the benefit of practice with the standardised patients as well as the benefits of being able to learn from their peers during observation and group discussion:

It was great to have the feedback after each student's session with the actor. It also allowed us to each hear and comment about each scenario and what worked well. 
The idea of learning within a supportive environment was of importance for students. Some adjectives that were used by students were "safe", "pressure free", "assessment free", and "non-judgemental". Finally, students portrayed a sense that they felt more prepared for work with real patients as a result of the experience. The interactions were described as realistic and of benefit, especially in the absence of a prior hospital-based placement.

\section{Theme 3: Clinical educators, help me maximise my learning when working with standardised patients}

There were several factors students felt could enhance their learning during the programme, and they wanted facilitators to consider them. Some students wanted more information about the programme prior to starting work with the standardised patients:

I am not usually anxious about meeting/gaining case history, but I was anxious as I did not know what to expect in this session.

Requests were made to simplify scenarios to reduce the cognitive load. There was also feedback requesting a longer programme and a greater array of scenarios. Feedback from facilitators and the actors was an inherent part of the programme. However, qualitative data highlighted a student preference for increased specificity and detail within this feedback. It was also requested that facilitators did not avoid negative feedback.

\section{Discussion}

\section{Anxiety, confidence and learning}

Our results indicated that within a speech-language pathology workplace placement, a brief standardised patient learning programme, targeting communication and interpersonal skills, had a positive impact on students' perceptions of working with real patients. Prior to the programme, the majority of students reported feeling moderately to severely anxious around the idea of interacting with real patients in their placement. Given these were final-year students, this data served as a useful reminder that it is not uncommon for experienced students to feel anxious as they embark on a new clinical placement (Brumfitt \& Freeman, 2007). Following the programme, there was a significant reduction in reported anxiety levels. As in Hill et al. (2013), the mechanisms behind this anxiety and its subsequent reduction were not studied. However, it is known that factors such as the degree of control in a clinical placement and the presence of assessment are anxiety provoking for final-year speech-language pathology students (Chan, Carter, \& McAllister, 1994). It is feasible that the clinical autonomy that this programme afforded to students combined with the lack of assessment may have contributed towards the reported reduction in student anxiety levels. Following the programme, there was also a statistically-significant increase in students' perceived confidence when anticipating working with real patients. This was a pleasing result given the high demand for diverse and flexible communicative skill within the healthcare setting.

Some parallels can be drawn between the results of this study and previous investigations within speech-language pathology. Undergraduate students in Hill et al.'s (2013) pre-post design study also reported a reduction in anxiety levels and an increase in confidence 
in the same eight skills following a foundation skills programme that involved work with standardised patients. Although our study utilised a very similar method of data collection, comparison is limited due to differences in other aspects of programme design. The current programme ran for 4 hours, with one tutorial and one session, whereas Hill et al.'s programme ran for multiple sessions and included standardised patient work, role plays and clinical workshops. When considering data from a similarly-designed survey in the broader area of simulation work, another pre-post study within speech-language pathology showed that graduate students reported significantly reduced anxiety levels and significantly increased confidence levels following participation in 4 hours of humanpatient simulation activities in paediatric dysphagia management. In comparison, levels did not reduce following lectures on the subject matter alone (Ward et al., 2015). This general trend of a post-programme reduction in perceived anxiety and increase in perceived confidence across three studies gives weight to the notion that, in line with findings from other healthcare disciplines, simulation appears to be a promising learning option for speech-language pathology students at various stages of their studies and within different areas of clinical competency.

Qualitative data provided rich information about students' perceived skill development during the programme. As a group, students felt that the programme assisted with developing their communication and interpersonal skills. Feedback suggested a patientcentred interpretation of communication that considered the individual, their behaviour, their emotions, and the environment. From a clinical educator's perspective, it was positive to see students reflecting on their own skill development in this holistic sense.

Qualitative analysis also provided insight into how students viewed their learning journey. Students' comments suggested that the programme encouraged them to engage in selfreflection in order to identify areas of focus for the placement. Reflection was encouraged in this programme through the use of small group discussion and survey completion. Although the scientific study of reflective practice is still in an emergent stage in healthcare, a systematic review across healthcare professions indicated that reflective practice can help with learning from experience (Mann, Gordon, \& Macleod, 2009). Furthermore, complex clinical situations can act as a catalyst for reflective practice (Mann et al., 2009). Learning in a reduced pressure environment is a commonly reported benefit of standardised patient work (Hill et al., 2010; Zraick, 2012) that was also reported in the current study. With the stress of assessment removed, students appeared to be able to better focus on rapport building with standardised patients. This was in line with qualitative evidence from the field of medicine that suggests assessment during standardised patient education may add pressure and, thus, reduce the student's ability to apply empathy (Parikh et al., 2015). Feedback has been deemed to be a crucial element to enhance learning during simulated education (McGaghie, Issenberg, Petrusa, \& Scalese, 2010). Furthermore, supported discussion and reflection, occurring after the actual simulation experience, have been described as crucial parts of the simulated-learning process (Herge et al., 2013). Students in the current study expressed the value of learning through practice, peer observation, supported discussion and feedback. Physiotherapy students have also reported that learning from peers and having the opportunity for feedback are important parts of the simulated learning process (Dennis et al., 2017). Engaging in 
peer observation prior to participation in simulation activity may in fact bolster student performance on specific domains, such as communication (Livsey \& Lavender-Stott, 2015). When designing standardised patient programmes, clinical educators should be aware of the myriad of ways in which they can exploit student learning both within a simulation scenario and beyond.

It is unclear if the programme led to performance gains within the placement. However, results are pleasing in terms of the likely positive impact on student self-efficacy. Previous research has indicated that there is a positive relationship between the speech-language pathologist's clinical self-efficacy and their clinical performance (Pasupathy \& Bogschutz, 2013). Results of a large study within nursing suggested that measures taken to improve student self-efficacy were likely to positively influence student wellbeing and learning. The authors suggested that self-efficacy could be strengthened through affirmation of learning in feedback after simulation and real clinical experiences (Gibbons, Dempster, \& Moutray, 2011). Future research that provides more objective information about learning outcomes in standardised patient programmes will afford educators a better insight into this matter.

\section{Perceptions of the programme}

When students are sent on a workplace clinical placement, the assumption is that learning will occur through supervised work with real patients. Therefore, there was a risk that students would view a standardised patient programme within a workplace-placement setting as superfluous to needs. However, this study demonstrated that the redesign of a traditional workplace-placement model to include standardised patient work was positively received by students. All students felt that the programme should be included for future student groups. This reinforces the words of Barrows (1993) who has described the standardised patient as "not a technique to be used only when there is a lack of real patients" (p. 446).

As demonstrated by the final qualitative theme, students provided constructive feedback around how they believed the programme should be developed in order to maximise their learning. Student preference for more information about the programme prior to starting work with the standardised patients was particularly salient and has been expressed in other simulation studies. For example, medical students participating in an end-of-life-care training programme with standardised patients wanted more detailed information prior to the learning experience (Parikh et al., 2015). Pre-simulation trepidation can also exist for qualified interdisciplinary healthcare professionals (Ross et al., 2013). Student feedback reminds us that it is important that facilitators do not inadvertently create more anxiety by not being clear enough about requirements within a clinical placement (Chan et al., 1994). Students also wanted increased exposure to the programme. This is not necessarily realistic in the context of a workplace setting and budgetary restrictions. Nonetheless, the eagerness of students to engage in and want more of this kind of programme positively supports the movement towards the integration of simulated learning into the speechlanguage-pathology university curricula (Macbean et al., 2013). 
WORK PLACEMENT AND STANDARDISED PATIENTS

\section{Limitations}

It is acknowledged that this was a small study without a control group. It also did not explore if the learning programme resulted in actual improved performance on clinical placement. Validated measures of anxiety were not used for data collection.

\section{Conclusion}

The utilisation of standardised patients within a workplace clinical placement is a promising way in which to target confidence in a specific clinical area, such as communication and interpersonal skills in this instance. This study has also shown that students perceived that skills developed during the standardised patient interactions were translatable to clinical placement. Further research within speech-language pathology that examines skill attainment following participation in such a programme is required. On a practical basis, the programme model presented in this paper appears to have relevance across a range of healthcare disciplines and could likely be applied to interdisciplinary practice scenarios.

\section{Acknowledgements}

This study was undertaken with support from Allied Health at Alfred Health.

\section{Funding and conflicts of interest}

The authors report no conflicts of interest. The authors alone are responsible for the content and writing of the paper.

\section{References}

Barrows, H. S. (1993). An overview of the uses of standardized patients for teaching and evaluating clinical skills. Academic Medicine, 68(6), 443-451.

Barrows, H., \& Abrahamson, S. (1964). The programmed patient: A technique for appraising student performance in clinical neurology. Journal of Medical Education, 39, 802-805.

Beattie, B. E., Kinney, J., Fitzgerald, M., Murdoch-Kinch, C. A., Guenther, M. K., Ridley, K., . . . Ramaswamy, V. (2014). Dental and dental hygiene students' perceptions of a standardized patient instructor conflict resolution program. Journal of Dental Education, 78(10), 1397-1404.

Bornais, J. A. K., Raiger, J. E., Krahn, R. E., \& El-Masri, M. M. (2012). Evaluating undergraduate nursing students' learning using standardized patients. Journal of Professional Nursing, 28(5), 291-296.

Bressmann, T., \& Eriks-Brophy, A. (2012). Use of simulated patients for a student learning experience on managing difficult patient behaviour in speech-language pathology contexts. International Journal of Speech-Language Pathology, 14(2), $165-173$. 
Brumfitt, S., \& Freeman, M. (2007). Speech and language therapy students' perceptions of learning in a university clinical setting. Learning in Health and Social Care, 6(4), 231-244.

Chan, J. B., Carter, S., \& McAllister, L. L. (1994). Sources of anxiety related to clinical education in undergraduate speech-language pathology students. Australian Journal of Human Communication Disorders, 22(1), 57-73.

Corbin, J., \& Stauss, A. (2008). Basics of qualitative research: Techniques and procedures for developing grounded theory (3rd ed.). Thousand Oaks, CA: Sage.

Dennis, D., Ng, L., \& Furness, A. (2017). First-year physiotherapy students who elect to participate in simulation-based learning activities benefit from the experience. Focus on Health Professional Education: A Multi-disciplinary Journal, 18(2), 89-101.

Gibbons, C., Dempster, M., \& Moutray, M. (2011). Stress, coping and satisfaction in nursing students. Journal of Advanced Nursing, 67(3), 621-632.

Gore, T., \& Thomson, W. (2016). Use of simulation in undergraduate and graduate education. AACN Advanced Critical Care, 27(1), 86-95.

Halkett, G. K. B., McKay, J., \& Shaw, T. (2011). Improving student's confidence levels in communicating with patients and introducing students to the importance of history taking. Radiography, 17(1), 55-60.

Herge, E. A., Lorch, A., DeAngelis, T., Vause-Earland, T., Mollo, K., \& Zapletal, A. (2013). The standardized patient encounter: A dynamic educational approach to enhance students' clinical healthcare skills. Journal of Allied Health, 42(4), 229-235.

Hill, A. E., Davidson, B. J., \& Theodoros, D. G. (2010). A review of standardized patients in clinical education: Implications for speech-language pathology programs. International Journal of Speech-Language Pathology, 12(3), 259-270.

Hill, A. E., Davidson, B. J., \& Theodoros, D. G. (2013). Speech-language pathology students' perceptions of a standardised patient clinic. Journal of Allied Health, 42(2), 84-91.

Kneebone, R. L., Scott, W., Darzi A., \& Horrocks, M. (2004). Simulation and clinical practice: Strengthening the relationship. Medical Education, 38(10), 1095-1102.

Levett-Jones, T., Pitt, V., Courtney-Pratt, H., Harbrow, G., \& Rossiter, R. (2015). What are the primary concerns of nursing students as they prepare for and contemplate their first clinical placement experience? Nurse Education in Practice, 15(4), 304-309.

Lincoln, Y., \& Guba, E. (1985). Naturalistic inquiry. Thousand Oaks, CA: Sage.

Livsey, K., \& Lavender-Stott, E. (2015). Impact of vicarious learning through peer observation during simulation on student behavioural measures. Focus on Health Professional Education: A Multi-disciplinary Journal, 16(4), 64-73.

Macbean, N., Theodoros, D., Davidson, B., \& Hill, A. E. (2013). Simulated learning environments in speech-language pathology: An Australian response. International Journal of Speech-Language Pathology, 15(3), 345-357. 
Mann, K., Gordon, J., \& MacLeod, A. (2009). Reflection and reflective practice in health professions education: A systematic review. Advances in Health Sciences Education, 14(4), 595-621.

McGaghie, W. C., Issenberg, S. B., Petrusa, E. R., \& Scalese, R. J. (2010). A critical review of simulation-based medical education research: 2003-2009. Medical Education, 44(1), 50-63.

McKenna, L., Innes, K., French, J., Streitberg, S., \& Gilmour, C. (2011). Is history taking a dying skill? An exploration using a simulated learning environment. Nurse Education in Practice, 11(4), 234-238.

Parikh, P. P., Brown, R., White, M., Markert, R. J., Eustace, R., \& Tchorz, K. (2015). Simulation-based end-of-life care training during surgical clerkship: Assessment of skills and perceptions. Journal of Surgical Research, 196(2), 258-263.

Pasupathy, R., \& Bogschutz, R. J. (2013). An investigation of graduate speech-language pathology students' SLP clinical self-efficacy. Contemporary Issues in Communication Science and Disorders, 40, 151-159.

Ross, A., Anderson, J., Kodate, N., Thomas, L., Thompson, K., Thomas, B., . . Jaye, P. (2013). Simulation training for improving the quality of care for older people: An independent evaluation of an innovative programme for inter-professional education. BMJ Quality \& Safety, 22(6), 495-505.

Schwartz, V. S., Rothpletz-Puglia, P., Denmark, R., \& Byham-Gray, L. (2015). Comparison of standardized patients and real patients as an experiential teaching strategy in a nutrition counseling course for dietetic students. Patient Education and Counseling, 98(2), 168-173.

SPSS Inc. (2007). Statistical package for the social sciences: SPSS for Windows (Version 16.0) [Computer software]. Chicago, IL: Author.

Syder, D. (1996). The use of simulated clients to develop the clinical skills of speech and language therapy students. European Journal of Disorders of Communication, 31(2), 181-192.

Ward, E. C., Hill, A. E., Nund, R. L., Rumbach, A. F., Walker-Smith, K., Wright, S. E., ... Dodrill, P. (2015). Developing clinical skills in paediatric dysphagia management using human patient simulation (HPS). International Journal of Speech-Language Pathology, 17(3), 230-240.

Watson, K., Wright, A., Morris, N., McMeeken, J., Rivett, D., Blackstock, F., . . Jull, G. (2012). Can simulation replace part of clinical time? Two parallel randomised controlled trials. Medical Education, 46(7), 657-667.

Zraick, R. (2012). Review of the use of standardized patients in speech-language pathology clinical education. International Journal of Therapy and Rehabilitation, 19(2), 112-118.

Zraick, R. I., Allen, R. M., \& Johnson, S. B. (2003). The use of standardized patients to teach and test interpersonal and communication skills with students in speechlanguage pathology. Advances in Health Sciences Education, 8(3), 237-248. 